\section{Specialist management of routine dental procedures in adults with refractory epilepsy}

\author{
N. Ransford, ${ }^{* 1}$ I. Soryal, ${ }^{2}$ D. McCorry, ${ }^{2}$ J. W. Sander, ${ }_{1}^{3}$ F. Duncan ${ }^{4}$ \\ and N. Huggins ${ }^{5}$
}

VERIFIABLE CPD PAPER

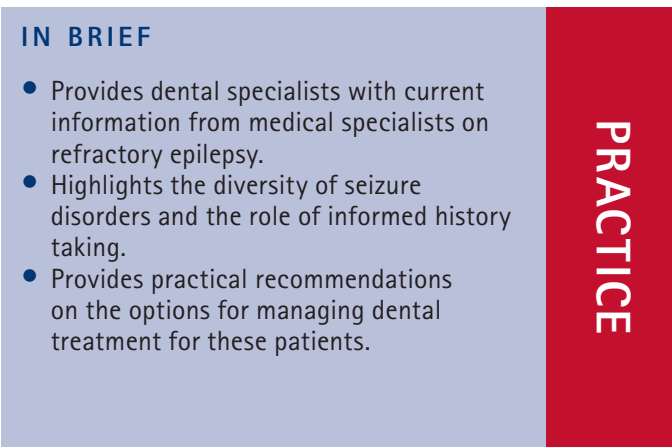

\begin{abstract}
Little published information exists about the management of dental treatment procedures for people with epilepsy who, despite their medication, continue to have seizures. This paper draws on relevant literature in neurology and anaesthetics to provide a multi-speciality consensus on methods of assessment and adjunctive treatment options in order to manage the risk of a clinically significant seizure occurring during a procedure. It aims to enhance current guidelines and practice in the provision of specialist care for this diverse group.
\end{abstract}

\section{INTRODUCTION}

Between 20 to 30\% of all people with epilepsy are refractory to current available antiepileptic drugs (AEDs) and continue to have seizures. ${ }^{1}$ In the UK, an estimated 100,000 people with epilepsy need continuing specialist neurological input and while some respond to surgical intervention, over 35,000 continue to have more than one seizure per month. ${ }^{2}$

People in this refractory group may present to dental services with a high level of treatment need as they often have relatively poor oral health ${ }^{3}$ as well as traumatised teeth. ${ }^{4}$ Many are referred to specialists in special care dentistry (SCD) whose caseload in primary care typically contains around a third of people taking AEDs. ${ }^{5}$ Others may be treated by specialists in restorative dentistry or prosthodontics.

It has been common practice for people who have seizures to have their dental treatment done in hospital under general anaesthesia (GA). ${ }^{6}$ The use of 'excessive precautions, restrictions, and management errors' has however been questioned, ${ }^{7}$ and dentistry has undergone a revolution in the use of conscious sedation as an alternative to GA. Also over the past decade, our

'Consultant in Special Care Dentistry, Birmingham Community Healthcare NHS Trust; ${ }^{2}$ Consultant Neurologist, ${ }^{4}$ Consultant Anaesthetist ${ }^{5}$ Consultant neuroanaesthetist, Queen Elizabeth Hospital, Birmingham; ${ }^{3}$ Professor of Neurology and Clinical Epilepsy, National Hospital for Neurology and Neurosurgery, London

*Correspondence to: Mr Nick Ransford

Email: nick.ransford@nhs.net

\section{Refereed Paper}

Accepted 11 December 2013

DOI: $10.1038 /$ sj.bdj.2014.247

${ }^{\circledR}$ British Dental Journal 2014; 216: 403-407 understanding of epilepsy has been accelerated by international collaborative research coordinated by the International League Against Epilepsy, and the growth of several prominent epilepsy charities. Many patients and carers have become expert in managing their seizures and perceive the risk from a seizure in a dental surgery to be no different from one occurring at home. It is therefore timely to review practice.

In this paper, we aim to evaluate current knowledge on refractory epilepsy as applied to the provision of routine dental treatment and to present recommendations based on a multi-speciality consensus. We cover the incidence and clinical significance of seizures during dental procedures, the identification of people in whom this is more likely to occur, and the roles of preprocedural oral sedation, intravenous conscious sedation, GA and the hospital setting as adjunctive treatment options.

It is important to bear in mind three fundamental points about seizures: firstly, seizure disorders exhibit considerable diversity and individual variation; secondly, epileptic seizures are almost always unprovoked and occur randomly; and thirdly, many non-epileptic conditions can mimic an epileptic seizure.

Other aspects of epilepsy in relation to oral health and dentistry have been comprehensively covered elsewhere, ${ }^{8-11}$ as have the specific issues relating to vagal nerve stimulation devices $(\mathrm{VNS})^{12}$ and the ketogenic diet. ${ }^{13}$

\section{INCIDENCE OF SEIZURES IN RELATION TO DENTAL PROCEDURES}

The often random nature of epileptic seizures makes the chance occurrence of one within the relatively short window of a dental appointment relatively low. Seizures have been reported as being the third most common type of adverse medical event in people attending general dental practices, but as the overall incidence of all types of events was 0.7 per dentist per year, ${ }^{14,15}$ seizures in this context are rare.

In hospitalised patients undergoing general surgery under GA, the frequency of perioperative seizures in people known to have epilepsy was found to be $3.4 \% .{ }^{16}$ In those treated with regional local anaesthesia, the corresponding figure was 5.8\%. ${ }^{17}$ The main factors involved were insufficient systemic levels of AED due to missed or changed doses, reduced absorption due to changes in gastro-intestinal motility, or people with frequent seizures or a seizure within 24 hours of baseline. No relation was found with the type of anaesthesia or surgery.

In dental patients a number of factors known to trigger epileptic seizures may coincide with a dental visit. Most notably, some can be significantly anxious and extreme cases present with sleep deprivation, fatigue and hyperventilation. Those presenting to special care dentists often also have coexisting neurological or developmental conditions associated with epilepsy, ${ }^{18}$ or are taking medication which may lower the seizure threshold such as psychotropics, tricyclic antidepressants, recreational drugs ${ }^{19}$ or alcohol abuse. ${ }^{20}$

Non-epileptic seizures can also occur. In particular, dissociative seizures triggered by medical procedures are increasingly being recognised and are often associated with a history of psychological trauma and abuse. ${ }^{21,22}$ One estimate suggested that up to a fifth of all people referred to specialist 
epilepsy centres have dissociative seizures. ${ }^{23}$ These can usually be distinguished from epilepsy by their gradual onset, forced eye closure with resistance to opening, responsiveness to noxious stimuli and the absence of injuries such as tongue biting and incontinence. ${ }^{24}$ In other instances, non-epileptic seizures may be due to syncope, panic attacks, hypoglycaemia, stroke, and in small children, fever.

Finally, there have been rare reports of seizures associated with the administration of dental local anaesthetics. Although anticonvulsant at sub toxic doses, ${ }^{25}$ an inadvertent intravascular injection of local anaesthetic can result in a temporary surge to a toxic level at which a convulsive seizure may occur. This is more likely with rapid administration in less than 60 seconds and with inferior alveolar nerve blocks. ${ }^{26}$

\section{CLINICAL SIGNIFICANCE}

Within the spectrum of epilepsy disorders, the seizure types of most significance during dental procedures are focal seizures with impaired consciousness ('complex partial seizures') and convulsive seizures (CS) of either primary or secondary origin. Teenagers and young adults most often have CS which may also occur throughout the whole life cycle. ${ }^{27}$ As well as unconsciousness, in a CS the person may go rigid often crying out, followed by convulsive movement involving all four limbs, cyanosis and sometimes incontinence. Convulsions are almost always self-limiting and rarely last more than a few minutes, but they are usually followed by a period of postictal drowsiness, confusion or sleep. People experiencing CS are at less risk of adverse sequelae in a supportive clinical environment than out on the street or sleeping alone in bed. Nevertheless, prolonged convulsions incur risks of physical injuries and hypoxia due to respiratory compromise. Irreversible neurological damage arising from ongoing seizure activity may occur, ${ }^{28}$ but this is a rare occurrence in clinical practice.

What is considered a 'prolonged' seizure varies for each individual but would typically be defined as over two to three minutes of convulsing. In addition, some individuals have seizures which occur in clusters of repeated seizures within a few minutes or hours. The likelihood of treatment resistance rises exponentially with the time of seizing. ${ }^{27,29}$ Over a 30 minute period, this state, or one in which there are two or more seizures with incomplete recovery of consciousness, is the epidemiological definition of status epilepticus (SE). This has a mortality of $10-20 \%,{ }^{30}$ although these figures included two thirds where death was from an underlying primary cause. In clinical

\begin{tabular}{|c|c|}
\hline Seizure factor & Description \\
\hline Type & Focal or convulsive seizures involving unconsciousness \\
\hline Frequency & Occurring on a daily or weekly basis \\
\hline Duration & A history of prolonged seizures, status epilepticus or seizure clusters \\
\hline Palliative seizure therapy & $\begin{array}{l}\text { Using rescue medication (rectal, buccal, intranasal benzodiazepines), a VNS } \\
\text { device, a ketogenic diet, or where epilepsy surgery is planned }\end{array}$ \\
\hline Medication issues & $\begin{array}{l}\text { AED changes within the last six months, missed dose(s), current gastro-intesti- } \\
\text { nal disturbance affecting absorption } \\
\text { Currently taking other drugs that may lower the seizure threshold }\end{array}$ \\
\hline Neurological syndromes & $\begin{array}{l}\text { Brain malformations including tuberous sclerosis, Sturge-Weber syndrome, } \\
\text { neurofibromatosis, cerebral palsy, Lennox-Gastaut syndrome, Down's syn- } \\
\text { drome, Fragile X syndrome, Angelman syndrome, Rett syndrome. } \\
\text { May also include traumatic brain injury, Alzheimer's disease and stroke }\end{array}$ \\
\hline
\end{tabular}

practice it has been suggested that any seizure lasting more than five minutes should be treated as SE and appropriate early treatment instigated..$^{31,32}$

\section{IDENTIFICATION OF PATIENTS MORE LIKELY TO HAVE A PERIOP- ERATIVE EPILEPTIC SEIZURE}

Table 1 summarises several factors which can be sought from the patient's history to identify individuals who may be more likely to have a clinically significant epileptic seizure during a treatment procedure.

\section{PREPROCEDURAL SEDATION}

In deciding on seizure preventive measures, the length and invasiveness of the procedure is a key factor. Simple procedures of less than 30 minutes usually require no special measures other than staff able to provide good rapport and confident reassurance. For people who are anxious and have stress-induced seizures, oral benzodiazepines (BZD) are not only anxiolytic but also have potent GABA-mediated anticonvulsive properties. Unfortunately, there is little supporting evidence for the effectiveness of this preprocedural application as the randomness of epileptic seizures makes it difficult to conduct clinical trials. One small study of situational seizure prevention, however, found that $10 \mathrm{mg}$ of oral clobazam achieved abolition or reduction of seizures in around half the cases. ${ }^{33}$ This regime would need to be prescribed by a neurologist or GP and given 30 minutes before the procedure. Oral diazepam (5-10 mg) is an alternative, prescribable by a dentist and given two hours before the procedure, although its sedative side effect may make this less useful.

Oral BZD's have also been recommended before a GA for people with epilepsy to reduce preoperative anxiety, and to prevent seizures on induction, on emergence from anaesthesia and during the recovery period. ${ }^{34}$

\section{CONSCIOUS SEDATION}

Nitrous oxide inhalation sedation is a useful technique for people with epilepsy who have mild to moderate dental anxiety. ${ }^{35}$ However, a considerable proportion of those referred to specialists in SCD not only need multiple extractions and restorations, but are also unable to tolerate treatment without the use of intravenous sedation (IVS) or general anaesthesia. Conscious sedation with midazolam via the intravenous route achieves enhanced anxiolytic and anticonvulsant effects, and has been recommended for people who have uncontrolled epilepsy. ${ }^{35}$ Again there is little direct evidence for this specific application. However, numerous studies have established midazolam as a mainstay in the acute control of seizures, ${ }^{29}$ and there is a range of animal experiments demonstrating the effectiveness of IV BZDs, including midazolam, in blocking chemically and electrically induced seizures. ${ }^{36-38}$ A single case report exists of seizures occurring in an adult dental patient with epilepsy undergoing treatment using midazolam. ${ }^{39}$

However, IV midazolam does have some disadvantages for people with epilepsy. Firstly, the efficacy of IV midazolam is reduced by BZD tolerance that may develop in people taking clobazam and clonazepam as add-on AED therapy. This also includes lorazepam which is sometimes used for behavioural reasons. ${ }^{40}$ People may also require larger doses of IV midazolam if they are taking liver cytochrome P450 enzymeinducing agents such as carbamazepine, phenytoin, or barbiturates. ${ }^{41}$

Secondly, reversal of sedation with flumazenil may trigger a seizure in people with poorly controlled epilepsy ${ }^{42}$ or those taking add-on oral BZD therapy. ${ }^{43-45}$ The effect of flumazenil in reversing the anticonvulsant effect of IV diazepam has been demonstrated in one animal experiment involving chemically induced convulsions. ${ }^{38}$ 
Table 2 Practical recommendations for managing dental procedures in patients with poorly controlled epilepsy

\begin{tabular}{|c|c|}
\hline 1. Seizure history taking & $\begin{array}{l}\text { Ascertain the typical nature and pattern of seizures for that individual and } \\
\text { consult with the neurologist and/or specialist epilepsy nurse on their personal } \\
\text { seizure management plan. } \\
\text { All people with refractory epilepsy should be under ongoing neurological care } \\
\text { with an annual review and many will have an individualised seizure manage- } \\
\text { ment protocol which should be obtained. } \\
\text { Check for recent changes in the normal seizure pattern and where possible } \\
\text { arrange for treatment to take place when they are in a seizure free phase. }\end{array}$ \\
\hline 2. AED medication & $\begin{array}{l}\text { Ensure AED compliance and that they continue to take them up until shortly } \\
\text { before the procedure, with a sip of water if having a GA. } \\
\text { Defer treatment in those whose normal seizure pattern has deteriorated, or } \\
\text { their AED regime has altered due to a recently changed prescription, or compro- } \\
\text { mised absorption due to GI disturbance. }\end{array}$ \\
\hline $\begin{array}{l}\text { 3. Manage the stress } \\
\text { response }\end{array}$ & $\begin{array}{l}\text { Consider preprocedural oral BZD sedation from } 24 \text { hours before the appoint- } \\
\text { ment particularly where sleep deprivation is likely. } \\
\text { Ensure alcohol and recreational drugs have been avoided in the preceding } \\
\text { three days. } \\
\text { People presenting in acute pain should have necessary emergency treatment } \\
\text { for relief of their symptoms, with invasive or definitive treatment deferred to } \\
\text { achieve control of their sleep and anxiety. }\end{array}$ \\
\hline $\begin{array}{l}\text { 4. Other management } \\
\text { advice }\end{array}$ & $\begin{array}{l}\text { Ask people to report any aura. } \\
\text { Have rescue medication such as buccal or intransasal midazolam ready for } \\
\text { possible use. } \\
\text { Consider placing an IV cannula before the procedure starts. } \\
\text { Check blood glucose to ensure the absence of hypoglycaemia. } \\
\text { Involve carers or family members who are familiar with their seizures and any } \\
\text { postictal effects such as confusion, emotional lability or agitation. } \\
\text { Ensure effective use of an aspirating local anaesthetic technique and consider } \\
\text { restricting the number of cartridges. }\end{array}$ \\
\hline $\begin{array}{l}\text { 5. Protocol for seizure } \\
\text { management (see also } \\
\text { Resuscitation Councilibo) }\end{array}$ & $\begin{array}{l}\text { Calm observation with airway support and supplemental oxygen as necessary. } \\
\text { Avoid restraint. } \\
\text { For a non cannulated patient, give } 10 \mathrm{mg} \text { buccal or intranasal midazolam after } \\
\text { the seizure has lasted twice as long as the patient's usual seizure, or after four } \\
\text { minutes, whichever is sooner. In the event of a second seizure following admin- } \\
\text { istration of buccal midazolam, call an ambulance. } \\
\text { For a cannulated patient, give IV midazolam in } 1-2 \mathrm{mg} 60 \text { sec increments } \\
\text { titrated to effect to control the seizure. } \\
\text { If a seizure occurs in a patient already sedated with IV midazolam, give a further } \\
\text { minimum titrated dose to control the seizure and call an ambulance } \\
\text { Any single prolonged seizure lasting more than five minutes, call an ambulance } \\
\text { whether treatment has been possible or not. }\end{array}$ \\
\hline 6. Training & $\begin{array}{l}\text { Specialist dental practitioners dealing with people with frequent seizures should } \\
\text { access training in seizure management which is often available locally from } \\
\text { specialist epilepsy nurses. They must maintain current ILS certification including } \\
\text { the use of airway devices. Those using oral and intravenous midazolam must } \\
\text { comply with the relevant national guidelines and training requirements. }\end{array}$ \\
\hline
\end{tabular}

Thirdly, IV midazolam may not achieve sufficient operative conditions in people with marked uncooperative behaviour due to a learning disability, of whom many also have epilepsy. One audit found that one in five such cases required GA. ${ }^{46}$

Finally while hypoxia is unlikely in a carefully titrated and closely monitored dental sedation procedure, severe hypoxia is a well-known cause of seizures and supplemental oxygen has been recommended for people with epilepsy. ${ }^{25}$ Also sedation should be avoided in those who also have compromised airway or respiratory function.

The role of propofol sedation in people with epilepsy has not been definitively established. One review of over 500 case reports found seizure-like phenomena occurring in patients both with and without when oral haemorrhage control is likely to be difficult. GA provides optimum operating conditions for an extended period when there is a large amount of treatment, the procedure is likely to be lengthy or intricate, or when treatment completion in a single visit is essential. Similarly when there is extreme uncooperative behaviour due to a severe learning disability, GA provides a virtual guarantee of being able to provide treatment. This is an imperative when there are acute oral symptoms and possible failure using IVS needs to be avoided.

GA, however, also has disadvantages for people with poorly controlled epilepsy. As well as its overall mortality rate of 1 in $220,000,{ }^{54}$ seizures can be triggered by problems related to the continuity of AED therapy during the pre- and postop periods, by metabolic disturbance or by fasting-related hypoglycaemia..$^{55}$ Seizures due to anaesthetic drugs are rare. One study in an epilepsy cohort undergoing interventions under GA that were unlikely to alter the seizure threshold, such as magnetic resonance imaging, found that seizures occurred in $2 \% .{ }^{56}$ Nevertheless, it is perhaps unsurprising that EEG studies have demonstrated that GA drug induced seizures occur more frequently in people with epilepsy. ${ }^{35}$ In terms of drug choice, there is no ideal anaesthetic regime. Seizure-like activity is normal during induction of and emergence from anaesthesia, and most anaesthetic drugs have convulsant and anticonvulsant properties. ${ }^{57}$ There is also innate individual variation in seizure susceptibility. The most conclusive evidence shows that sevoflurane, enflurane and etomidate are more likely to induce epileptiform EEG activity. ${ }^{35}$

\section{THE HOSPITAL SETTING}

The use of hospital facilities for dental and other minor procedures needs to be justified in terms of appropriate use of resources. Three groups of patients have risk factors which clearly require a medically supported hospital setting:

Firstly, those with a history of prolonged focal, convulsive or cluster seizures, or a previous episode of SE as there is evidence that this group has a genetic predisposition to recurrence. ${ }^{28}$ Delays in treatment, due to an ambulance transfer and a wait in the accident and emergency department while specialist medical expertise is summoned, may put them at risk of the adverse sequelae of ongoing seizure activity. Their treatment may also require advanced airway adjuncts, positive pressure ventilation, second stage AEDs such as barbiturates, and cardiac inotropic agents.

Secondly, those with severe cardiac, cerebrovascular and chronic respiratory comorbidities associated with epilepsy, ${ }^{58}$ as these 
may be exacerbated by the sympathetic surge of a prolonged seizure and result in a life threatening crisis.

Thirdly, those with a history of difficult to manage postictal agitation or dissociative behaviour which may require specialist neurological or psychiatric support.

In terms of seizure frequency per se, a medically supported hospital setting should be considered for those with daily convulsive seizures as the likelihood of occurrence during treatment is higher. For those with less frequent seizures, there is a lack of consensus as to the most appropriate setting. In our view where seizures are occurring weekly or less, and in the absence of any significant medical or behavioural factors as described above, treatment in a non-medically supported setting by a dental specialist is justifiable with the appropriate use of oral pre procedural sedation or IVS as seizure preventive measures. We are aware of current guidelines based on seizure frequency, ${ }^{59}$ but assessment should also take into account the other factors determining seizure significance listed in Table 1 , together with the relative merits of adjunctive treatment options. A pragmatic, validated scale of seizure severity designed for the purpose would aid these case selection decisions but is currently unavailable.

\section{PRACTICAL RECOMMENDATIONS FOR MANAGING DENTAL PROCE- DURES IN PATIENTS WITH POORLY CONTROLLED EPILEPSY}

Whichever adjunctive treatment modality or setting is chosen, Table 2 summarises a number of actions that can be taken to manage individuals in whom a seizure is more likely to occur during a dental procedure.

\section{CONCLUSIONS}

Seizures that occur during dental procedures are infrequent. However, specialist clinicians who deal with people who have refractory epilepsy should be aware of the diversity of possible causes, the need to control precipitating factors, and the range of possible seizure prevention options. They should also have training in seizure management.

The history is of fundamental importance in identifying individuals more likely to have a clinically significant perioperative seizure, and careful case selection is essential in deciding on adjunctive treatment methods and setting. Rapport building and anxiety control are essential, and certain patients have been identified for whom preprocedural sedation, IV midazolam sedation, general anaesthesia and treatment in a hospital setting are considerations. Further work is needed to devise a seizure severity scale to inform decisions on treatment setting.
This paper illustrates the range of options and the importance of a multi-speciality approach in the appropriate management of dental treatment for these people.

The authors wish to thank several people who have generously given of their time in discussing various aspects of this paper, in particular Catherine Doherty and Nicole Toghil, Specialist Epilepsy Nurses, and Guy Hollis, General Dental Practitioner.

Kwan P, Sander J W. The natural history of epilepsy: an epidemiological view. J Neurol Neurosurg Psychiatry 2004; 75: 1376-1381.

2. Rugg-Gunn F J, Sander J W. Management of chronic epilepsy. BMJ 2012; 345: e4576.

3. Karolyhazy K, Kovacs E, Kikovics P, Fejerdy P, Aranyi $Z$. Dental status and oral health of patients with epilepsy: an epidemiologic study. Epilepsia 2003; 44: 1103-1108.

4. Buck D, Baker G A, Jacoby A, Smith D F, Chadwick D W. Patients' experiences of injury as a result of epilepsy. Epilepsia 1997; 38: 439-444.

5. Ransford N, Tate D, Randall C. Retrospective audit of the prescribed systemic medication taken by adults using salaried primary care dental services in Warwickshire and implications for dental care. J Disab Oral Health 2009; 10: 169-174.

6. Hulland S, Sigal M. Hospital based dental care for persons with disabilities: a study of patient selection criteria. Spec Care Dent 2000; 20: 131-138.

7. Devinsky 0 , Nordli D. Procedures and anaesthesia in patients with epilepsy. In Engel J, Pedley T (eds) Epilepsy, a comprehensive textbook. Volume 2. 2nd ed. pp 2027-2036. Wolters Kluwer Health, Lippincott Williams and Wilkins, 2008

8. Dougall A, Fiske J. Access to special care dentistry, part 5. Safety. Br Dent J 2008; 205: 177-190.

9. Robbins M. Dental management of special needs patients who have epilepsy. Dent Clin N Amer 2009; 53: 295-309.

10. Jacobsen P, Eden O. Epilepsy and the dental management of the epileptic patient. J Contemp Dent Pract 2008; 9: 1-14.

11. Fiske J, Boyle C. Epilepsy and oral care. Dent Update 2002; 29: 180-187.

12. Lisowska P, Daly B. Vagus nerve stimulation therapy (VNST) in epilepsy - implications for dental practice. Br Dent J 2012; 212: 69-72.

13. Sharma A, Mathur V P. Refractory epilepsy and the ketogenic diet: pathophysiological aspects and possible implications in dental practice. J Indian Soc Pedod Prev Dent 2011; 29: 182-192.

14. Girdler N M, Smith D G. Prevalence of emergency events in British dental practice and emergency management skills of British dentists. Resuscitation 1999; 41: 159-167.

15. Atherton G J, McCaul J A, Williams S A. Medical emergencies in general dental practice in Great Britain. Part 1. Their prevalence over a 10-year period. Br Dent J 1999; 23: 72-79.

16. Niesen A D, Jacob A K, Aho L E et al. Perioperative seizures in patients with a history of a seizure disorder. Anesth Analg 2010; 111: 729-735.

17. Kopp S L, Wynd K P, Horlocker T T, Hebl J R, Wilson $L$. Regional blockade in patients with a history of a seizure disorder. Anesth Analg 2009; 109: 272-278.

18. Robbins M. Dental management of special needs patients who have epilepsy. Dent Clin N Amer 2009; 53: 295-309.

19. Dhuna A. Epileptogenic properties of cocaine in humans. Neurotoxicity 1991; 12: 621-626.

20. Gordon E, Devinsky O. Alcohol and marijuana: effects on epilepsy and use by patients with epilepsy. Epilepsia 2001 Oct; 42: 1266-1272.

21. Reuber M, Enright S M, Goulding P J. Postoperative pseudostatus: Not everything that shakes is epilepsy. Anaesthesia 2000; 55: 70-78

22. Collard B, Johnson S, Cascarini L, Lee S Pseudoseizures and surgery. Br Dent J 2010; 208: 3-4.

23. Bendbadis S, Allen Hauser W. An estimate of the prevalence of psychogenic non-epileptic seizures. Seizure 2000; 9: 280-281.
24. Mellers J D. The approach to patients with "nonepileptic seizures". Postgrad Med J 2005; 81: 498-504.

25. Modica P A, Tempelhoff R, White P F. Pro and anticonvulsive effects of anesthetics Part 2. Anesth Analg 1990; 70: 433-444.

26. Malamed S F. Medical emergencies in the dental office. 6th ed. Mosby, 2007.

27. Zifkin B, Dravet C. Generalied tonic-clonic seizures. In Engel J, Pedley T (eds). Epilepsy - a comprehensive textbook. Volume 12 nd ed. pp 553-562. Wolters Kluwer Health, Lippincott Williams and Wilkins, 2008.

28. Treiman D M. Generalised convulsive status epilepticus. In Engel J, Pedley T (eds) Epilepsy - a comprehensive textbook. Volume 1.2nd ed. pp665-676. Wolters Kluwer, Lippincott Williams and Wilkins, 2008.

29. Shinnar S. Who is at risk for prolonged seizures? J Child Neurol 2007; 22: 14S-20S.

30. Rosenow F, Arzimanoglou A, Baulac M. Recent developments in treatment of status epilepticus: a review. Epileptic disord 2002; 4: S41-S51.

31. Lowenstein D H, Bleck T, MacDonald R L. It's time to revise the definition of status epilepticus. Epilepsia 1999: 40: 120-122.

32. National Institute for Health and Clinical Excellence. The epilepsies: the diagnosis and management of the epilepsies in adults and children in primary and secondary care. Clinical guideline 137. NICE, 2012. Guideline available online at: www.nice.org.uk/ cg137 (accessed January 2014).

33. Wolf P. Acute administration of benzodiazepines as part of treatment strategies for epilepsy. CNS Neurosci Ther 2011; 17: 214-220.

34. Voss L J, Sleigh M D, Barnard J P, Kirsch H E. The howling cortex: seizures and general anaesthetic drugs. Anesth Anal 2008; 107: 1689-1703.

35. Malamed S F. Sedation, a guide to patient management. 4th ed. Mosby, 2003.

36. Loscher W, Schmidt D. Which animal models should be used in the search for new antiepileptic drugs? A proposal based on experimental and clinical considerations. Epilepsy Res 1988; 2: 145-181.

37. Turski L. Substantia nigra regulates action of antiepileptic drugs. Brain Res 1990; 520: 232-239.

38. Yokoyama M, Benson K T, Arakawa K, Goto H. Effects of flumazenil on intravenous lidocaineinduced convulsions and anticonvulsant property of diazepam in rats. Anesth Analg 1992; 75: 87-90.

39. Robb N D. Epileptic fits under intravenous midazolam sedation. Br Dent J 1996; 181: 178-179.

40. Robb N D, Hargreave S A. Tolerance to intravenous midazolam as a result of oral benzodiazepine therapy: a potential problem for the provision of conscious sedation in dentistry. Anesth Pain Control Dent 1993; 2: 94-97.

41. Spina E, Perucca E. Clinical significance of pharmacokinetic interactions between antiepileptic and psychotropic drugs. Epilepsia 2002; 43(suppl 2): 37-44.

42. Schulze-Bonhage A, Elger C E. Induction of partial epileptic seizures by flumazenil. Epilepsia 2000; 41 : 186-192.

43. Fiske J, Boyle C. Epilepsy and oral care. Dental Update 2002; 29: 108-187.

44. H, DiSalvo RP, Imhoff TE. Fatal seizures after flumazenil administration in a patient with mixed overdose. Ann Pharmacother. 1994; 28: 1347-1349.

45. S. Flumazenil and seizures: analysis of 43 cases. Clin Ther. 1992; 14: 292-305.

46. Ransford N J, Manley M C G, Lewis D A, Thompson $S \mathrm{~A}$ et al. Intranasal/ intravenous sedation for the dental care of adults with severe disabilities: a multicentre prospective audit. Br Dent J 2010; 208: 565-569.

47. W, Tramèr MR, Seeck M. Seizure like phenomena and propofol: a systematic review. Neurology 2002; 58: 1327-1332.

48. Leitch J A, Sutcliffe N, Kenny G N. Patient maintained sedation for oral surgery using a targetcontrolled infusion of propofol - a pilot study. Br Dent J 2003: 194: 43-45.

49. Smith M, Smith S J, Scott C A, Harkness W F. Activation of the electrocorticogram by propofol 
during surgery for epilepsy. B J.Anaesth 1996; 76 : 499-502.

50. Wang B, Bai Q, Jiao X, Wang E, White P F. Effect of sedative and hypnotic doses of propofol on the EEG activity of patients with or without a history of seizure disorders. J Neurosurg Anesthesiol 1997; 9: 335-340.

51. Oei-Lim V L, Kalkman C J, Bouvy-Berends E C et al. A comparison of the effects of propofol and nitrous oxide on the electroencephalogram in epileptic patients during conscious sedation for dental procedures. Anesth Analg 1992; 75: 708-714.

52. Meyer, S, Shamdeen M G, Kegel B et al. Effect of propofol on seizure like phenomena and electroencephalographic activity in children with epilepsy vs children with learning difficulties. Anaesthesia 2006 ; 61: 1040-1047.

53. Samra S K, Sneyd J R, Ross D A, Henry T R. Effects of propofol sedation on seizures and intracranially recorded epileptiform activity in patients with partial epilepsy. Anesthesiology 1995; 82: 843-851.

54. Lagasse R. Anesthesia safety: model or myth? A review of the published literature and analysis of current original data. Anesthesiology 2002; 97 : 1609-1617.

55. Schauwecker PE. The effects of glycemic control on seizures and seizure-induced excitotoxic cell death BMC Neurosci 2012;13: 94. Article available online at: http://www.biomedcentral.com/1471-2202/13/94 (accessed January 2014).

56. Benish S M, Cascino G D, Warner M E, Worrell G A, Wass C T. Effect of general anaesthesia in patients with epilepsy: a population based study. Epilepsy Behav 2010; 17: 87-89.

57. Modica P A, Tempelhoff R, White P F. Pro and anticonvulsive effects of anesthetics Part 1. Anesth analg 1990: 70: 303-315

58. Elliot J O, Shneker B, Charyton C, Layne Moore J. Comorbidity, health screening, and quality of life among persons with a history of epilepsy. Epilepsy Behav 2009; 14: 125-129.

59. Dental Sedation Teachers Group DSTG) and the Society for the Advancement of Anaesthesia in Dentistry (SAAD). Conscious sedation: a referral guide for dental practitioners. 2012. Guide available online at: http://www.dstg.co.uk/conscioussedation/ (accessed January 2014).

60. Resuscitation Council. Medical emergencies and resuscitation - Standards for clinical practice and training for dental practitioners and dental care professionals in general dental practice. London: Resuscitation Council, 2006 (revised 2012). Information available online at: http://www.resus. org.uk/pages/MEdental.pdf (accessed January 2014). 